\title{
DNA copy number changes in young gastric cancer patients with special reference to chromosome 19
}

\author{
A Varis ${ }^{1,3}$, B van Rees ${ }^{2,3}$, M Weterman'2, A Ristimäki', J Offerhaus ${ }^{2}$ and S Knuutila*, \\ 'Departments of Pathology and Medical Genetics, Haartman Institute and Helsinki University Central Hospital, University of Helsinki, POB 400 \\ (Haartmaninkatu 3, 4th floor), FIN-00029 HUS, Helsinki, Finland; ${ }^{2}$ Department of Pathology, Academic Medical Center, Meibergdreef 9 , I 05 AZ \\ Amsterdam, The Netherlands
}

\begin{abstract}
Only a few cytogenetic and genetic studies have been performed in gastric cancer patients in young age groups. In the present study we used the comparative genomic hybridisation (CGH) method to characterise frequent DNA copy number changes in 22 gastric cancer patients of 45 years or younger and three gastric cancer cell lines established from patients younger than 45 years. Analysis of DNA copy number changes revealed frequent DNA copy number increases at chromosomes 17q (52\%), 19q (68\%) and 20q (64\%). To confirm the $\mathrm{CGH}$ results and to characterise the amplicon region on the most frequently amplified chromosome, chromosome 19, we carried out fluorescence in situ hybridisation (FISH) analysis and Southern blot analysis. Fluorescence in situ hybridisation with the bacterial artificial chromosome (BAC) clone mapped to $19 q 12$ indicated a copy number increase in all eight tumour specimens studied. Southern blot analysis of six tumour specimens and three tumour cell lines, with five probes mapped to the $19 q 12-13.2$ region, suggested cyclin $\mathrm{E}$ to be one of the candidate target genes in the $19 \mathrm{q}$ region for gastric cancer tumorigenesis. Cyclin $\mathrm{E}$ protein overexpression was verified in tumours with amplification on chromosome 19. Further studies are required to investigate the biological and clinical significance of $19 \mathrm{q}$ amplicon and cyclin $\mathrm{E}$ upregulation in gastric cancer of young patients.
\end{abstract}

British Journal of Cancer (2003) 88, 1914-1919. doi:10.1038/sj.bjc.6600969 www.bjcancer.com

(c) 2003 Cancer Research UK

Keywords: gastric cancer; comparative genomic hybridisation; 19q; cyclin E

Gastric cancer is the second most frequent cancer worldwide (Parkin et al, 1999), but in young age groups it is rather uncommon. Several studies have been published about gastric cancer in young patients aged 45 years or younger (Kokkola et al, 1996; Maehara et al, 1996; Theuer et al, 1996; 1998; Semba et al, 1998; Rugge et al, 1999; Haruma et al, 2000; Kath et al, 2000). These studies have suggested differences between clinicopathological and histological outcome in gastric cancer in young and elderly age groups. In young patients, gastric cancer has been suggested to arise with a more aggressive disease and poorer prognosis. Histologically the diffuse type of gastric cancer according to Laurén (1965) is suggested to be predominant in young age groups. Helicobacter pylori infection is assessed to be a risk factor also for young patients in both histological types.

Numerous cytogenetic and genetic aberrations have been described in gastric cancer in elderly patients. These include frequent DNA copy number gains in chromosomes $8 \mathrm{q}, 17 \mathrm{q}$ and $20 \mathrm{q}$ and losses in chromosome 4 by comparative genomic hybridisation (CGH) (Kokkola et al, 1997, 1998; El-Rifai et al, 1998, 2001). Several oncogenes, tumour suppressor genes and mismatch repair genes are assumed to be associated with the development and progression of gastric tumours. Two of the most investigated genes are ERBB2 and TOPO2A making them possible prognostic markers of gastric cancer (Seregni et al, 2001).

*Correspondence: Dr S Knuutila; E-mail: Sakari.Knuutila@helsinki.fi

${ }^{3} \mathrm{~A}$ Varis and $\mathrm{B}$ van Rees contributed equally to this work.

Revised 9 December 2002; accepted 5 March 2003
Only a few cytogenetic and genetic investigations have been reported about gastric cancer in young patients (Maehara et al, 1996; Semba et al, 1998; Haruma et al, 2000; Rugge et al, 2000). So far no reports of sporadic/nonfamilial gastric cancer have indicated any specific genetic characteristic arising in young patients compared to elderly patients. Germline E-cadherin mutations have been found in patients with familial cases of the diffuse type gastric cancer (Gayther et al, 1998).

In order to find out whether the genetic changes in younger patients differ from those in older patients, we studied DNA copy number changes in gastric cancer of young patients. Using CGH, we analysed 22 tumour samples of patients aged 45 years or younger, and three gastric cancer cell lines established from patients who were younger than 45 years. To verify CGH results and to characterise the amplicon on the most frequently amplified chromosome, chromosome 19, we performed fluorescence in situ hybridisation (FISH) analysis for eight patients and Southern blotting analysis for six patients as well as for three cell lines derived from gastric carcinomas of young patients. In addition, we used immunohistochemical analysis for four patients.

\section{MATERIALS AND METHODS}

\section{Cell lines}

Three gastric cancer cell lines, TMK-1 (obtained from the Department of Pathology, Hiroshima University School of Medicine, Hiroshima, Japan), and MKN-7 and MKN-74 (obtained 
from the Second Department of Pathology, Fukushima Medical College, Fukushima, Japan) were used in this study (Table 1). Cell lines were cultured under the recommended conditions. All three cell lines were established from male subjects, ages between 21 and 39 years. Two cell lines (MKN-7, MKN-74) were histologically classified as well-differentiated tubular adenocarcinoma and one cell line (TMK-1) as poorly differentiated adenocarcinoma.

\section{Patients}

Archival paraffin-embedded specimens from 24 young gastric cancer patients were obtained from the Department of Pathology at the Helsinki University Central Hospital, Finland, the Department of Pathology at the Jorvi Hospital, Espoo, Finland, and the Department of Pathology at the Academic Medical Center, Amsterdam, Netherlands.

In all, 15 patients had intestinal type of gastric cancer, seven patients had diffuse type of gastric cancer, and two patients were diagnosed with mixed type of gastric cancer. The median age of patients was 39 years (range 18-45 years), and 14 of them were male patients. Two of the patients had family history (cases 11 and 24) of gastric cancer.

Gastric carcinomas were classified by an experienced pathologist. A distinction was made between the two main histological subtypes and in early and advanced carcinomas.

\section{Comparative genomic hybridisation (CGH)}

For CGH, DNA was extracted from three cell lines, paraffinembedded specimens from 22 young gastric cancer patients, and from the peripheral blood of a healthy male or female (reference DNA) using standard protocols. Comparative genomic hybridisation was performed and analysed as described previously (El-Rifai et al, 1997; Varis et al, 2001).

\section{Nuclei extraction and FISH}

The nuclei from the paraffin-embedded tissues were extracted from the eight patients and two reference samples. Paraffin sections of $10 \mu \mathrm{m}$ that were very rich in tumour cells were used in nuclei isolation of tumour samples. As a probe for the interphase FISH, we used bacterial artificial chromosome (BAC) clone CTC525D6 (AC011474; Research Genetics, Huntsville, AL, USA). The nuclei extraction, FISH and analysis were performed as described previously (Hemmer et al, 2001), except origin of two reagents, biotin-14-dATP and Cot-1 DNA, which were purchased from Gibco BRL (Geithessburg, MD, USA).

\section{Southern blotting}

Genomic DNA for Southern blotting was extracted from three cell lines and the sections of the frozen material of six patient samples using standard protocols. Southern blotting and hybridisations were performed by standard laboratory methods (Weterman et al, 1996). The percentage of tumour cells was estimated on an HEstained section of the frozen material.

Southern blot analysis was performed using phosphorimager (Fuji) and AIDA software v.2.41. The signal intensity in the lanes containing tumour DNA was divided by the intensity obtained for the corresponding normal DNAs. Both signals were adjusted for loading differences and background using a $\beta$-globin control probe. The threshold value for amplification was 2.5. If corresponding DNA from normal tissue was not available (cell lines and case 23), intensity for normal DNA was based on the average intensity of signals from all other normal DNAs.

Five cDNA image clones for Southern blotting were obtained from the RZPD (Deutsches Ressourcenzentrum für Genomforschung $\mathrm{GmbH}$, Heubnerweg 6, D-14059 Berlin, Germany).
The clones were sequence verified and the corresponding inserts were isolated using appropriate restriction analysis and purification prior to labelling. The clones used were IMAGp998O145473 (CCNE), IMAGp998B125762 (CEBPA), IMAGp998K066030 (TGFB), IMAGp9980131258 (BCL3) and IMAG p998B152412 (AKT2).

\section{Immunohistochemistry}

Immunohistochemistry for cyclin $\mathrm{E}$ was performed using the monoclonal antibody CYE5 (Neomarkers, Fremont, CA, USA) in $1: 40$ dilution. Briefly, paraffin-embedded specimens were sectioned $(4 \mu \mathrm{m})$, deparaffinised, blocked for endogenous peroxidase activity by immersion in $0.3 \% \mathrm{H}_{2} \mathrm{O}_{2}$ in methanol for $20 \mathrm{~min}$ and heat treated at $100^{\circ} \mathrm{C}$ in $(\mathrm{pH}$ 9) for $10 \mathrm{~min}$. Nonspecific binding sites were blocked in 5\% normal goat serum for $10 \mathrm{~min}$ following the incubation for $1 \mathrm{~h}$ with the primary antibody at room temperature. The Powervision+poly-HRP detection system (ImmunoVision Technologies, Co, Daly City, CA, USA) was used to visualise the antibody binding sites with 3,3-diaminobenzidine + as a chromogen. Sections were counterstained with haematoxylin.

\section{RESULTS}

\section{Comparative genomic hybridisation}

To identify DNA sequence copy number changes in young patients with gastric cancer, 25 gastric carcinoma patient samples and three cell lines were included in CGH analysis. A summary of the gains and losses detected by CGH is shown in Figure 1. Detailed clinical and karyotypic data are presented in Table 1, which is available as a supplement on the BJC web site, www.nature.com/bjc/. DNA copy number changes were more frequent in intestinal cases (13 out of 14 cases, 93\%) than in diffuse cases, of which only one of the six cases was abnormal (17\%). DNA copy number changes were detected in both mixed gastric carcinoma and all three gastric carcinoma cell lines. The most common changes were gains at chromosome $19 \mathrm{q}$ (17 out of $25,68 \%$ ), at chromosome $20 \mathrm{q}$ (16 out of $25,64 \%$ ) and at chromosome 17q (13 out of 25, 52\%). Losses were frequent at chromosome 4 (10 out of $25,40 \%)$.

In the group of intestinal carcinomas DNA copy number increase was frequently observed in chromosomal arms $20 \mathrm{q}(86 \%)$, $17 \mathrm{q}(71 \%)$ and $19 \mathrm{q}(71 \%)$. Frequent losses were seen at $4 \mathrm{q}(50 \%)$ and $5 q(29 \%)$. High-level amplifications were present on the q-arm of chromosome 17, p-arm of chromosome 18, q-arm of chromosome 19 and in chromosome 20. In all three cell lines derived from young patients gains were detected for chromosomes 5, 11, 19 and 20. High-level amplifications were again seen on chromosomes 19 and 20, but also in chromosomes 7 and 11 .

\section{Interphase FISH}

In order to confirm the results obtained by $\mathrm{CGH}$, eight gastric cancer cases of the intestinal type (cases 2, 8, 9, 10,11, 12, 14 and 15) with amplification on chromosome 19 or the $19 q$ arm and two normal stomach tissues were investigated by FISH using BAC CTC-525D6, which maps to 19q12, as a probe. This also allows for specification of copy number changes in the tumours examined. On average two signals were observed in two normal stomach tissue preparations. One case (case 10), which showed high-level amplification on chromosome 19 by CGH, had an average of over 20 copies per nucleus for BAC CTC-525D6. Other samples of tumor tissue also showed increases in copy numbers for BAC CTC525D6 the range being between 2.5 and 5.5 copies per nucleus (Table 1). 
Table I Clinical characteristics, CHG findings, Southern blotting and FISH results of tumour specimens and cell lines

\begin{tabular}{|c|c|c|c|c|c|c|c|}
\hline No. & Age/sex & Histology & Stage & CGH results/gains & CGH results/losses & $\begin{array}{l}\text { Southern blotting } \\
\text { results, amplified } \\
\text { genes }\left(\text { ratio }^{a}\right)\end{array}$ & $\begin{array}{l}\text { Interphase FISH } \\
\text { signals (BAC CTC- } \\
\text { 525D6)/average } \\
\text { signals/nucleus) }\end{array}$ \\
\hline 1 & $42 / M$ & Intestinal & Advanced & $5 p, 8 q,|7 q| 2$-qter, 19 cen-q|3.2 & 4, 5q, 6qcen-q22, 9p22-pter & - & - \\
\hline 2 & $39 / \mathrm{M}$ & Intestinal & Advanced & |Iqcen-q14, 19 & 4 & - & 2.5 \\
\hline 3 & $4 \mathrm{I} / \mathrm{M}$ & Intestinal & Advanced & 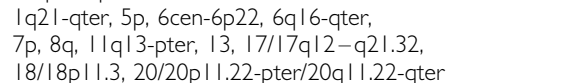 & $\begin{array}{l}\text { Ip31.2-p21.2, 2q21-qter, } 4 p \\
4 q 24-q t e r, 5 q c e n-q 31 \\
|2 q| 5-q 22\end{array}$ & - & - \\
\hline 4 & $44 / \mathrm{F}$ & Intestinal & Early & $\begin{array}{l}\text { Iq21-qter, 6p | |2.2-pter, 7q21.I-pter, I I qcen-q |3, } \\
\text { I2p, I 6q1 I.2-pter, 17q22-pter/ } \\
\text { I7qcen-q21.32, 19, } 20\end{array}$ & $3,4,9 p, 12 q 15-q 22$ & - & - \\
\hline 5 & $44 / \mathrm{M}$ & Intestinal & Advanced & $\begin{array}{l}|q 2|-q 23,8 p|2-p t e r, 9 p| 3 \text {-qter, }|| q \mid 3, \\
|7 q,| 8 p|| .3, \mid 9,20\end{array}$ & $18 q$ & - & - \\
\hline 6 & $45 / M$ & Intestinal & Advanced & 19,20 & No losses & - & - \\
\hline 7 & $4 I / M$ & Intestinal & Advanced & $\begin{array}{l}\text { |q21-q25, 3q26.2-qter, 6pcen-p22, | | q |4-q12, } \\
\text { 12, 17/17q, 19, 20q/20q, } 22\end{array}$ & $4,5 q \mid 4.2-q 23,18 q$ & - & - \\
\hline 8 & $42 / M$ & Intestinal & Advanced & $\begin{array}{l}\text { 4p|5.3-pter, 5p|5.I-pter, Xq24-qter, 7, 8q, } \\
\text { I0q, | |qcen-q|4, I2p|2-pter, I6, I 7q, I9, } \\
\text { 20q| | .2-qter }\end{array}$ & $4 q, 6 q 25.2-p / 2.2,13$ & - & 2.7 \\
\hline 9 & 39/M & Intestinal & Advanced & $\begin{array}{l}1 \mathrm{q}, 7,8 \mathrm{q}, 10 \mathrm{p}, 17 \mathrm{q} 21 \text {-qter, 18p, } \\
19,20\end{array}$ & No losses & - & 3.8 \\
\hline 10 & $43 / M$ & Intestinal & Advanced & $\begin{array}{l}\text { |q, 2q34-qter, 7pter-q2|,|2q|4-q|5, 17, } \\
|8 p, 19 /| 9 \text { cen-q|3.|, 20q|2-qter }\end{array}$ & 4, 5p/3-q23.2, 9p24 & CCNE (3I) & $>20$ \\
\hline 11 & $37 / \mathrm{F}$ & Intestinal & Advanced & $\begin{array}{l}\text { Iq, 5p 15.1-pter, Xq/Xq22-qter, 8q, 9q, 13, I6p, } \\
\text { 17cen-q23, 19, } 20\end{array}$ & No losses & AKT2 (4.7) & 3.0 \\
\hline 12 & $45 / \mathrm{M}$ & Intestinal & Advanced & $|1| 2 p|| .2-,p|2,19,20 q| 1.22$-qter & No losses & No amplification & 2.9 \\
\hline 13 & 30/F & Intestinal & Advanced & Normal & Normal & - & - \\
\hline 14 & $28 / M$ & Intestinal & Advanced & $\begin{array}{l}\text { 7p|3-pter, 8q, |3q|2-q|4.1I, 17q|2-q21.31, } \\
19 \text { cen-q|3.2, 20q }\end{array}$ & No losses & - & 5.5 \\
\hline 15 & $39 / \mathrm{M}$ & Mixed & Advanced & $\begin{array}{l}\text { Ip31.2-pter, Iq, 2q34-qter, } 5 p \mid 3 \text {-pter, 7pter-q31.2/ } \\
7 p|3-21,8 q| 2 \text {-qter, } \\
9 q 21.12 \text {-qter, } 1|q| 2.2-q \mid 3, \\
12,15,17,19,20 / 20\end{array}$ & I lq22.3-qter & No amplification & 2.5 \\
\hline 16 & $42 / \mathrm{F}$ & Mixed & Advanced & $16 p$ & No losses & - & - \\
\hline 17 & $42 / \mathrm{F}$ & Diffuse & Advanced & Normal & Normal & - & - \\
\hline 18 & $39 / F$ & Diffuse & Advanced & Normal & Normal & - & - \\
\hline 19 & $4 \mathrm{I} / \mathrm{M}$ & Diffuse & Advanced & Normal & Normal & - & - \\
\hline 20 & $38 / \mathrm{M}$ & Diffuse & Advanced & Normal & Normal & - & - \\
\hline 21 & $39 / \mathrm{F}$ & Diffuse & Advanced & $8 q, 13,16 p, 19 p$ & $8 p, 9 p, 16 q$ & - & - \\
\hline 22 & $18 / \mathrm{F}$ & Diffuse & Advanced & Normal & Normal & - & - \\
\hline 23 & $43 / M$ & Diffuse & Advanced & Sample not available & Sample not available & CCNE (3) & - \\
\hline 24 & $36 / M$ & Intestinal & Advanced & Sample not available & Sample not available & No amplification & - \\
\hline 25 & TMK-I 2I/M & & $\begin{array}{l}\text { Poorly differentiated } \\
\text { adenocarcinoma }\end{array}$ & 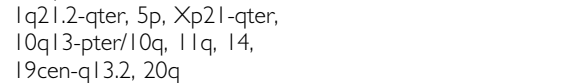 & $\begin{array}{l}\text { 4,6q, 8q13-pter, 12p, } \\
13,18 q 21 \text {-qter, } 21\end{array}$ & CEBPA (4.1) & - \\
\hline 26 & MKN-7 39/M & & $\begin{array}{l}\text { Well differentiated } \\
\text { tubular adenocarcinoma }\end{array}$ & 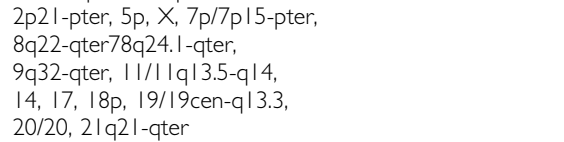 & $\begin{array}{l}\text { Ip32-q21.1, 4q24-pter, } \\
\text { 6q15-q23, 8p21-pter, } \\
\text { 9q21.32-pter, 10, } \\
\text { 12q21.32-pter, 15q21-pter, } \\
\text { 18q22-qter }\end{array}$ & $\begin{array}{l}\text { CCNE (II) CEBPA } \\
\text { (4.6) AKT2 (2.9) }\end{array}$ & - \\
\hline 27 & MKN-74 37/M & & $\begin{array}{l}\text { Well differentiated } \\
\text { tubular adenocarcinoma }\end{array}$ & 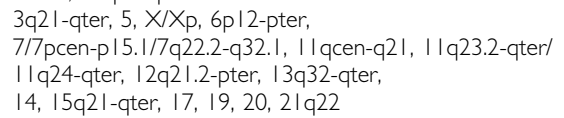 & $\begin{array}{l}\text { Iq21-p22, Iq42-qter, 4p 14-qter, } \\
6 q 15 \text {-qter, 8q1 I.2I-q21.3, } \\
9 q 34.11 \text {-pter, } 18 q 21 \text {-q22.1 }\end{array}$ & $B C L 3(3)$ & - \\
\hline
\end{tabular}

Straight line $=$ sample not available or no indication for the Southern blotting of FISH. ${ }^{\text {T}}$ The threshold value for amplification $=2.5$. 

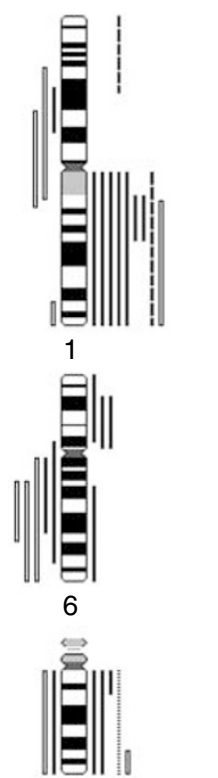

13

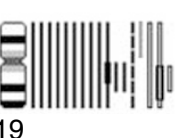

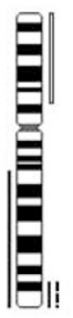

2
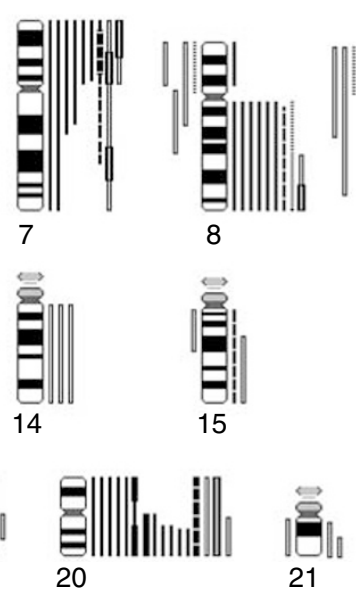

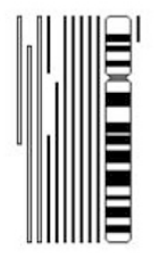

4

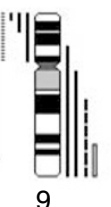

9

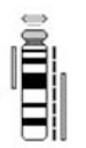

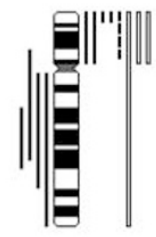

5

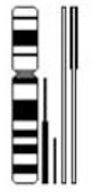

X

Figure I Summary of gains and losses in 22 tumours of young gastric cancer patients and three cell lines. Gains are shown on the right sides of chromosomes and losses on the left sides. Intestinal tumours, solid lines; mixed tumours, broken lines; diffuse tumours, dotted lines; cell lines, open bars. High-level amplifications are marked with a thick bar.

\section{Southern blotting}

To characterise the amplified region on chromosome 19 in more detail, Southern blot analysis was performed for six gastric cancer tumours (cases 10,11, 12, 15, 23 and 24) of which frozen material was available and five normal controls (cases 10,11,12, 15 and 24) of the same patients. In addition, three gastric cancer cell lines (MKN-7, MKN-74 and TMK-1) derived from young patients were analysed. Five cDNA clones that mapped to the $19 q 12-13.2$ region [CCNE, CEBPA, AKT2, TGFB and BCL3, mentioned in the order of their location on chromosome 19 (Table 1)] were used as probes. The highest amplification level was seen for CCNE (cyclin E) in case no 10 (ratio 31) and cell line MKN-7 (ratio 11). Amplifications were also detected at a lower level for CEBPA and AKT2. Amplification of $B C L 3$ was only detected in one case and TFGFB was not amplified in any of the samples.

\section{Cyclin E expression}

Four samples from young gastric cancer patients were immunostained for cyclin E. Two of the cases (cases 17 and 19, Table 1) without any $19 \mathrm{q}$ abnormalities did not show overexpression of cyclin E (Figure 3), whereas the other two cases (cases 10 and 14, Table 1) with a 19q amplicon detected by other methods showed positive staining for cyclin E (Figures 2 and 3 ).

\section{DISCUSSION}

In the present study we used CGH to characterise DNA copy number changes in young patients with gastric cancer. The most frequent cytogenetic aberrations were gains seen at $17 q(52 \%), 19 q$ $(68 \%)$ and $20 \mathrm{q}(64 \%)$. DNA copy number changes were mostly detected in intestinal or mixed types of tumour, which is in agreement with our previous studies of gastric cancer tumours
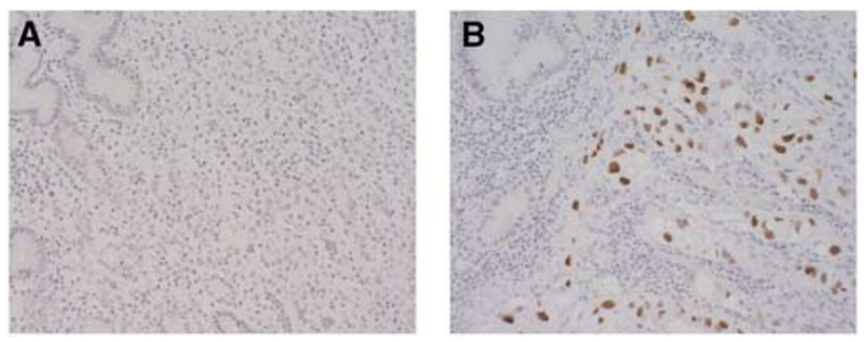

Figure 2 Immunohistochemical analysis of cyclin E protein expression in gastric cancer tumours. (A) Diffuse type of gastric cancer tumour without 19q amplicon, no detection of cyclin E overexpression and (B) Intestinal type of gastric cancer with $19 \mathrm{q}$ amplicon, increased nuclear staining of cyclin E detected.

(Kokkola et al, 1997, 1998). Our study of intestinal type of tumours, in which the mean age of the patients was 67 years, showed frequent gains in chromosomes $8 \mathrm{q}(45 \%), 17 \mathrm{q}(41 \%)$ and $20 \mathrm{q}(55 \%)$ and losses in chromosomes $4 \mathrm{q}(32 \%)$ and $18 \mathrm{q}(41 \%)$, whereas no abnormalities were observed for chromosome 19 . Our results of DNA copy number changes in older age group accord well with the results of the other CGH studies in older gastric cancer patients (Van Dekken et al, 2001; Wu et al, 2001). However, some dissimilarities between the published gastric cancer studies are found, for example, frequency of abnormalities in chromosome 19. In the study of Van Dekken et al (2001) gain at $19 q$ was involved in $30 \%$ of cases in older age group. Still, the frequency of the $19 q$ gain observed in our present study on young patients is significantly higher than previously indicated in gastric cancer.

The most remarkable difference we detected in relatively young patients compared to previous investigations was the frequency of 

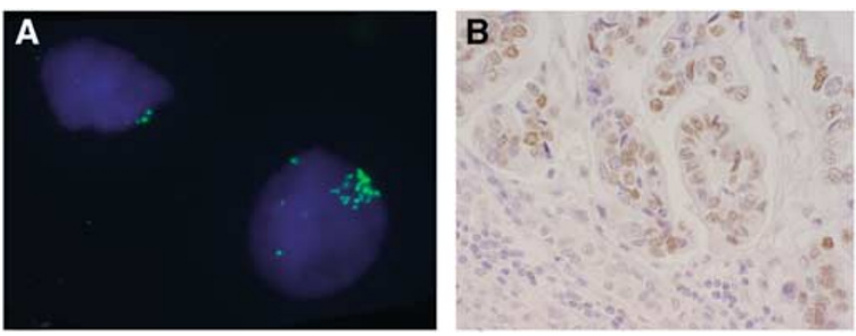

Figure 3 Fluorescence in situ hybridisation and immunohistochemical analysis of intestinal type of gastric cancer tumour (Case No. 10). (A) Fluorescence in situ hybridisation image of hybridisation with BAC probe targeting the $19 q \mid 2$ region (green signals). Normal nucleus with two signals on the left side and nucleus with amplification on the right side. (B) The same tumour indicating positive staining of cyclin E protein.

the $19 q$ amplicon. Frequent DNA sequence copy number increases at chromosome 19 in other cancers have been described in myeloma and plasmacytoma, small cell lung cancer, adrenocortical tumours (childhood) and pancreatic endocrine tumours (Knuutila et al, 1998, updated 2002, http://www.helsinki.fi/emg).

To confirm and narrow the target region on chromosome 19q, we performed FISH and Southern blotting analysis. The FISH study using a BAC probe which, mapped to 19q12, indicated a copy number increase in all studied tumour specimens in this region. One of the most likely candidate genes in this region is CCNE (cyclin E). Amplification of the cyclin E gene was identified in one cell line and two tumour specimens by Southern blotting. Three other genes, CEBPA, BCL3 and AKT2, showed lower amplification status than cyclin E, and Southern blot did not show any amplification in the TGFB gene. These facts indicate that the critical target segment is more probably located in the region between $19 \mathrm{q} 12$ and the centromere than in the 19q13.1-13.2 region. Immunohistochemical analysis of cyclin E protein demonstrated overexpression of cyclin $\mathrm{E}$ in tumours with $19 \mathrm{q}$ amplicon, but not in tumours without $19 \mathrm{q}$ abnormalities. Further studies are needed to investigate whether this region includes other genes, in addition to cyclin E, critical for gastric cancer development and progression. On the other hand, coamplification of neighbouring genes in the target segment, without upregulation, may have occurred (Varis et al, 2002). Previously a few reports have been published about findings of cyclin E upregulation in gastric cancer of older patients (Akama et al, 1995; Sakaguchi et al, 1997; Lin et al, 2000).

Overexpresssion of cyclin $\mathrm{E}$ has been suggested to correlate with the P53 expression, progression of gastric carcinoma and poorer prognosis (Sakaguchi et al, 1997). Cyclin E has an important role as a cell cycle regulator. After forming a complex with cdk2 cyclin $\mathrm{E}$ regulates the transition from the G1 phase to the $S$ phase in the cell cycle and, as such, may play a role in gastric carcinogenesis. In addition to gastric cancer, amplification and overexpression of cyclin $\mathrm{E}$ have been detected in several other carcinomas, including oesophageal cancer, ovarian cancer and sarcomas (Akama et al, 1995; Donnellan and Chetty, 1999; Lin et al, 2000).

\section{REFERENCES}

Akama Y, Yasui W, Yokozaki H, Kuniyasu H, Kitahara K, Ishikawa T, Tahara E (1995) Frequent amplification of the cyclin E gene in human gastric carcinomas. Jpn J Cancer Res 86: 617-621

Collins C, Rommens JM, Kowbel D, Godfrey T, Tanner M, Hwang SI, Polikoff D, Nonet G, Cochran J, Myambo K, Jay KE, Froula J, Cloutier T, Kuo WL, Yaswen P, Dairkee S, Giovanola J, Huchinson GB, Isola J, Kallioniemi OP, Palazzolo M, Martin C, Ericsson C, Pinkel D, Gray JW
In this study slight discrepancies between used methods may exist, caused by the fact that the probes used in FISH and Southern blot analysis are not overlapping and thus cover another genomic region, although all map to the $19 \mathrm{q} 12-13.2$ region. The BAC clone CTC-525D6 is mapped to $19 \mathrm{q} 12$, but it does not cover the region of CCNE. In addition, CGH and FISH were performed on the same paraffin-embedded material with enriched tumour cells, whereas frozen material with varying proportions of tumour cells was used for Southern blot analysis. This fact may mask the presence of amplifications in Southern blot analysis. Nevertheless, it is important to underline that high-level amplifications at $19 \mathrm{q}$ were observed by all methods used in this study.

Most of the patients had advanced stage of the tumour and for this reason we were not able to compare the correlation of chromosomal aberrations with the stages of the tumours.

The target genes in the other frequently amplified region, $17 \mathrm{q} 12-\mathrm{q} 21$, are well studied. In our previous research in gastric cancer xenografts and cell lines, amplified and overexpressed genes detected in this region were the well-known TOPO $2 \mathrm{~A}$ and $E R B B 2$, and one uncharacterised EST (Varis et al, 2002). TOPO2A and $E R B B 2$ are considered to be possible target genes in cancer therapy, especially in breast cancer (Cuello et al, 2001; Harris et al, 2001).

Amplification of $20 \mathrm{q}$ has been reported in different kinds of tumours. Several amplified and overexpressed genes have been identified on this chromosome, such as BTAK in gastric, breast and ovarian cancer, MYBL2 and ZNF217 in breast and ovarian cancer, $N A B C 1$ in breast cancer, TGIF2 and PTPN1 in ovarian and breast cancer, and AIB1 in gastric, ovarian, pancreatic and breast cancer (Collins et al, 1998; Knuutila et al, 1998; Ghadimi et al, 1999; Forozan et al, 2000; Imoto et al, 2000; Sakakura et al, 2000, 2001; Tanner et al, 2000). In addition to BTAK and AIB1, some of the other known oncogenes in the $20 \mathrm{q}$ region may also be target genes in gastric cancer.

To conclude, our study revealed frequent DNA copy number changes in young patients with intestinal and mixed types of gastric cancer and in gastric cancer cell lines established from young patients. The most frequently observed abnormalities were gains and high-level amplifications on chromosomes $17 q, 19 q$ and 20q. In addition, we identified one amplified and overexpressed target gene, cyclin E, in the most frequently amplified target segment of chromosome 19. Further studies would elucidate the biological and prognostic role of $19 \mathrm{q}$ amplicon and cyclin $\mathrm{E}$ upregulation in young patients with gastric cancer.

\section{ACKNOWLEDGEMENTS}

This work was supported by funding from the Finnish Cancer Foundation, Sigrid Jusélius Foundation and Helsinki Biomedicum foundation. We thank Toshimitu Suzuki, Second Department of Pathology, Fukushima Medical College, for providing cell lines MKN-7 and MKN-74 and Hiroshi Yokozaki, Department of Pathology, Hiroshima University School of Medicine, for providing cell line TMK-1 for the present study. We acknowledge the valuable help of Mirjam Polak for technical assistance.

(1998) Positional cloning of ZNF217 and NABC1: genes amplified a 20q13.2 and overexpressed in breast carcinoma. Proc Natl Acad Sci USA 95: $8703-8708$

Cuello M, Ettenberg SA, Clark AS, Keane MM, Posner RH, Nau MM, Dennis PA, Lipkowitz S (2001) Down-regulation of the erbB-2 receptor by trastuzumab (herceptin) enhances tumor necrosis factor-related 
apoptosis-inducing ligand-mediated apoptosis in breast and ovarian cancer cell lines that overexpress erbB-2. Cancer Res 61: 4892-4900

Donnellan R, Chetty R (1999) Cyclin E in human cancers (Review). FASEB 13: $773-780$

El-Rifai W, Frierson Jr HF, Moskaluk CA, Harper JC, Petroni GR, Bissonette EA, Jones DR, Knuutila S, Powell SM (2001) Genetic differences between adenocarcinomas arising in Barrett's esophagus and gastric mucosa. Gastroenterology 121: $592-598$

El-Rifai W, Harper JC, Cummings OW, Hyytinen E-R, Frierson Jr HF, Knuutila S, Powell SM (1998) Consistent genetic alterations in xenografts of proximal stomach and gastro-esophageal junction adenocarcinomas. Cancer Res 58: 34-37

El-Rifai W, Larramendy M, Björkqvist A-M, Hemmer S, Knuutila S (1997) Optimization of comparative genomic hybridization using fluorochrome conjugated to dCTP and dUTP nucleotides. Lab Invest 77: 699-700

Forozan F, Mahlamäki EH, Monni O, Chen Y, Veldman R, Jiang Y, Gooden GC, Ethier SP, Kallioniemi A, Kallioniemi OP (2000) Comparative genomic hybridization analysis of 38 breast cancer cell lines: a basis for interpreting complementary DNA microarray data. Cancer Res 60: 45194525

Gayther SA, Gorringe KL, Ramus SJ, Huntsman D, Roviello F, Grehan N, Machado JC, Pinto E, Seruca R, Halling K, MacLeod P, Powell SM, Jackson CE, Ponder BA, Caldas C (1998) Identification of germ-line Ecadherin mutations in gastric cancer families of European origin. Cancer Res 58: $4086-4089$

Ghadimi BM, Schrock E, Walker RL, Wangsa D, Jauho A, Meltzer PS, Ried $\mathrm{T}$ (1999) Specific chromosomal aberrations and amplifications of the AIB1 nuclear receptor coactivator gene in pancreatic carcinomas. $\mathrm{Am} \mathrm{J}$ Pathol 154: 525-536

Harris LN, Yang L, Liotcheva V, Pauli S, Iglehart JD, Colvin OM, Hsieh TS (2001) Induction of topoisomerase II activity after ErbB2 activation is associated with a differential response to breast cancer chemotherapy. Clin Cancer Res 7: 1497-1504

Haruma K, Ito M, Kohmoto K, Kamada T, Kitada Y, Yasui W, Tahara E, Kajiyama G (2000) Expression of cell cycle regulators and growth factor/ receptor systems in gastric carcinoma in young adults: association with Helicobacter pylori infection. Int J Mol Med 5: 185-190

Hemmer S, Wasenius V-M, Haglund C, Zhu Y, Knuutila S, Franssila K, Joensuu $\mathrm{H}$ (2001) Deletion of 11q23 and cyclin D1 overexpression are frequent aberrations in parathyroid adenomas. Am J Pathol 158: 13551362

Imoto I, Pimkhaokham A, Watanabe T, Saito-Ohara F, Soeda E, Inazawa J (2000) Amplification and overexpression of TGIF2, a novel homeobox gene of the TALE superclass, in ovarian cancer cell lines. Biochem Biophys Res Commun 276: 264-270

Kath R, Fiehler J, Schneider P, Höffken K (2000) Gastric cancer in very young adults: apropos four patients and literature. J Cancer Res Clin Oncol 126: $233-237$

Kokkola A, Monni O, Puolakkainen P, Larramendy ML, Victorzon M, Nordling S, Haapiainen R, Kivilaakso E, Knuutila S (1997) 17q21-21 amplicon, a novel recurrent genetic change in intestinal type of gastric carcinoma: a comparative genomic hybridization study. Genes Chromosomes Cancer 20: $38-43$

Kokkola A, Monni O, Puolakkainen P, Nordling S, Haapiainen R, Kivilaakso E, Knuutila S (1998) Presence of high-level DNA copy number gains reflects malignant transformation of gastric adenomas. Cancer Genet Cytogenet 107: 32-36

Kokkola A, Valle J, Haapiainen R, Sipponen P, Kivilaakso E, Puolakkainen $\mathrm{P}$ (1996) Helicobacter pylori infection in young patients with gastric carcinoma. Scand J Gastroenterol 31: 643-647

Knuutila S, Björkqvist AM, Autio K, Tarkkanen M, Wolf M, Monni O, Szymanska J, Larramendy ML, Tapper J, Pere H, El-Rifai W, Hemmer S, Wasenius VM, Vidgren V, Zhu Y (1998) DNA copy number amplifications in human neoplasms. Am J Pathol 152: 1107-1123

Laurén P (1965) The two histological main types of gastric carcinoma: diffuse and so-called intestinal-type carcinoma. APMIS 6: 209-222
Lin L, Prescott MS, Zhu Z, Singh P, Chun SY, Kuick RD, Hanash SM, Orringer MB, Glover TW, Beer DG (2000) Identification and characterization of a 19q12 amplicon in esophageal adenocarcinomas reveals cyclin $\mathrm{E}$ as the best candidate gene for this amplicon. Cancer Res 60: $7021-7027$

Maehara Y, Emi Y, Tomisaki S, Oshiro T, Kakeji Y, Ichiyoshi Y, Sugimachi K (1996) Age-related characteristics of gastric carcinoma in young and elderly patients. Cancer 77: $1774-1780$

Parkin MD, Pisani P, Ferlay J (1999) Global cancer statistics. CA Cancer J Clin 49: $33-64$

Rugge M, Busatto G, Cassaro M, Shiao Y-H, Russo V, Leandro G, Avellini C, Fabiano A, Sidoni A, Covacci A (1999) Patients younger than 40 years with gastric carcinoma: Helicobacter pylori genotype and associated gastritis phenotype. Cancer 85: 2506-2511

Rugge M, Shiao Y-H, Busatto G, Cassaro M, Strobbe C, Russo VM, Leo G, Parenti AR, Scapinello A, Arslan P, Egarter-Vigl E (2000) The p53 gene in patients under the age of 40 with gastric cancer: mutation rates are low but are associated with a cardiac location. Mol Pathol 53: $207-210$

Sakaguchi T, Watanabe A, Sawada H, Yamada Y, Yamashita J, Matsuda M, Nakajima M, Miwa T, Hirao T, Nakano H (1998) Prognostic value of cyclin E and p53 expression in gastric carcinoma. Cancer 82: $1238-1243$

Sakakura C, Hagiwara A, Yasuoka R, Fujita Y, Nakanishi M, Masuda K, Kimura A, Nakamura Y, Inazawa J, Abe T, Yamagishi H (2000) Amplification and over-expression of the AIB1 nuclear receptor coactivator gene in primary gastric cancer. Int J Cancer 89: 217-223

Sakakura C, Hagiwara A, Yasuoka R, Fujita Y, Nakanishi M, Masuda K, Shimomura K, Nakamura Y, Inazawa J, Abe T, Yamagishi H (2001) Tumour-amplified kinase $B T A K$ is amplified and overexpressed in gastric cancers with possible involvement in aneuploid formation. $\mathrm{Br} J$ Cancer 84: 824-831

Semba S, Yokozaki H, Yasui W, Tahara E (1998) Frequent microsatellite instability and loss of heterozygosity in the region including BRCA1 (17q21) in young patients with gastric cancer. Int J Oncol 12: 1245-1251

Seregni E, Ferrari L, Martinetti A, Bombardieri E (2001) Diagnostic and prognostic tumor markers in the gastrointestinal tract. Semin Surg Oncol 20: $147-166$

Tanner MM, Grenman S, Koul A, Johansson O, Meltzer P, Pejovic T, Borg A, Isola JJ (2000) Frequent amplification of chromosomal region 20q12q13 in ovarian cancer. Clin Cancer Res 6: 1833-1839

Theuer CP, de Virgilio C, Keese G, French S, Arnell T, Tolmos J, Klein S, Powers W, Oh T, Stabile B (1996) Gastric adenocarcinoma in patients 40 years of age or younger. Am J Surg 172: 473-477

Theuer CP, Kurosaki T, Taylor TH, Anton-Culver H (1998) Unique features of gastric carcinoma in the young. Cancer 83: 25-33

Van Dekken H, Alers JC, Riegman PHJ, Rosenberg C, Tilanus HW, Vissers K (2001) Molecular cytogenetic evaluation of gastric cardia adenocarcinoma and precursor lesions. Am J Pathol 158: $1961-1967$

Varis A, Puolakkainen P, Savolainen H, Kokkola A, Salo J, Nieminen O, Nordling S, Knuutila S (2001) DNA copy number profiling in oesophageal Barrett adenocarcinoma: comparison with gastric adenocarcinoma and esophageal squamous cell carcinoma. Cancer Genet Cytogenet 127: $53-58$

Varis A, Wolf M, Monni O, Vakkari M-L, Kokkola A, Moskaluk C, Frierson Jr H, Powell SM, Knuutila S, Kallioniemi A, El-Rifai W (2002) Targets of gene amplification and overexpression at $17 \mathrm{q}$ in gastric cancer. Cancer Res 62: $2625-2629$

Weterman MAJ, Wilbrink M, Geurts van Kessel A (1996) Fusion of the transcription factor TFE3 gene to a novel gene, $P R C C$, in $\mathrm{t}(\mathrm{X} ; 1)(\mathrm{p} 11 ; \mathrm{q} 21)-$ positive papillary renal cell carcinomas. Proc Natl Acad Sci USA 93: $15294-15298$

Wu M-S, Chang M-C, Huang S-P, Tseng C-C, Sheu J-C, Lin Y-W, Shun C-T, Lin M-T, Lin JT (2001) Correlation of histologic subtypes and replication error phenotype with comparative genomic hybridization in gastric cancer. Genes Chromosomes Cancer 30: 80-86 